\title{
OS ESPAÇOS LIVRES PÚBLICOS COMO EXPRESSÕES DE CENTRALIDADE
}

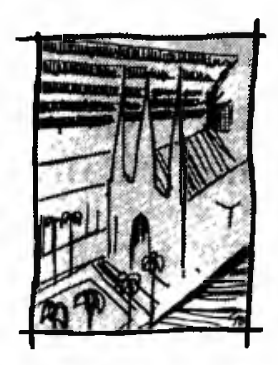

VLADIMIR BARTALINI

Estudos da História e de Geografia Urbana evidenciam a importância da circulação na organização espacial, mais especificamente na forma ção e desenvolvimento dos núcleos urbanos.

Pesquisando a estruturação da Grande São Paulo, Langenbuch chama a atenção para este fato ao se referir aos povoados que surgiram em torno dos pousos de tropas e mais tarde aos núcleos em torno das estações de trem, de cruzamentos rodoviários e de pontos iniciais e finais de linhas de ônibus. A própria denominação que utiliza para classificar tais núcleos é sugestiva desta influência: "povoado-estação" "subúrbio-estação" "subúrbio-entroncamento" "subúrbio-ônibus". Nestes pontos notáveis do espaço, onde ocorrem interrupções de viagem ou mudança de modalidade de transporte, acabam por se concentrarequipamentos comerciais e de serviços que, por mais modestos que sejam, conferem uma certa centralidade ao lugar.

O poder polarizador destes pontos é variável em função das características dos meios de transporte. Os trens de subúrbio e o metrô, transportando grande número de pessoas por viagem, circulando por vias exclusivas e com itinerário rígido têm pontos de parada bem definidos: as estações. De um modo geral nelas se verifica uma considerável concentração de pessoas e equipamentos. A vida em tono das estações terá assim uma componente ligada especificamente ao meio de transporte - concentração e dispersão nos embarques e desembarques-e outra ligada à própriacentralidade dolugar, que gera um uso mais complexo, composto pelas diversas funções que ali podem se desenvolver: habitações, comércio, serviços, lazer. Nelas se verifica uma vinculação forte e persistente entre o espaço físico e o uso que nele ocorre, devido à própria inércia dos objetos construídos. Define-se, assim, uma atração polar.

Já os ônibus transportam menos passageiros por viagem, têm itinerários mais flexíveis e pontos de parada dotados de maior mobilidade e mais próximos uns dos outros que, em geral, não apresentam as características de pólo encontradas nas estações. O mesmo ocorre com os trolebus, apesar dos itinerários fixose de uma certa inércia em seus pontos de parada ${ }^{2}$.

Há ainda outro aspecto que particulariza as estaçōes, que se poderia chamar de seu significado remoto. Surgidas no séc. XIX com as estradas de ferro, de início 
relacionadas com viagens longas, foram em seguida assimiladas pela vida cotidiana com os trens de subúrbio e mais tarde com o metrô. No entanto, pelo seu impacto, pela novidade de que eram portadoras, marcaram profundamente os lugares em que se instalaram, fixando-se no imaginário coletivo. Assim se refere Pierre Diaz-Pedregal às estações de estrada de ferro, ao tratar do significado dos espaços públicos: "Espaços não mais habitados, mas atravessados, não mais de vida, mas de trânsito, as estações produziram uma organização espacial muito particular: a animação ali é grande, o contato e a comunicação fáceis. Lugar de onde se parte mas também onde se chega, a estação é vivida simultaneamente como um espaço de separaçãoe de encontro. Não há muitos outros espaços públicos cuja carga emocional seja mais forte"”.

A importância das estações se traduziu na sua arquitetura. Independentemente dos lugares em que tenham ocorrido, elas sempre se destacaram dos edifícios vizinhos, seja pela monumentalidade, seja por um maior requinte construtivo, seja pela peculiaridade da sua função. O espaço externo que lhes corresponde, a "praça da estação" foi se constituindo aos poucos. Muitas das cidades dos primeiros países a serem servidos por estradas de ferro não têm praças de estação ou, se as têm, são pouco importantes ${ }^{4}$

A praça da estação é, assim, um dado relativamente novo que, na Europa, ocorreu sobretudo na Alemanha, na Suiça e em algumas cidades da Itália ou em outros lugares por ocasião de transferências de estações realizadas mais recentementes.

São Paulo tem as suas estações de trem mais centrais associadas a praças ou jardins, ainda que em dois dos casos os espaços livres precedessem às estações. A estação da Luz na verdade foi implantada em área do então Jardim Botânico. O que hoje se chama praça da Luz não passa de uma avenida larga que separa, em vez de unir, a estação do parque remanescente. A estação Roosevelt, no Brás, tem a sua frente a pequena praça Agente Cícero, que acomoda o edifício e que conduz ao largo da Concórdia, o antigo largo do Brás, de existência anterior à estação. Já a praça Júlio Prestes está vinculada desde a origem à estação do mesmo nome.

Também em vários bairros paulistanos servidos por ferrovias registra-se a ocorrência de praças ou, mais genericamente, espaços livres de uso público, junto às estações ${ }^{6}$.

Apesar das diferenças de tempo e de espaço, que separam a implantação das ferrovias e do metrô em São Paulo, algumas comparações podem ser tentadas.

A ferrovia foi um fator de urbanização (ou suburbanização) em áreas até então não urbanizadas, tendo nas estações o seu centro irradiador. $O$ metrô, meio de transporte urbano por excelência, serve a áreas centrais ou subcentrais, ou pelo menos de 
urbanização consolidada, e é um fator de transformação urbana. Nem sempre a maior intensidade desta transformação vai ocorrer imediatamente em tomo das estações. A complexidade já presente nos espaços não permite uma relação tão direta de causa e efeito. Mas certamente se verificam ali mudanças de uso e previsíveis alteraçōes de fluxo de pessoas e veículos, suficientes para impressionar a paisagem e o ambiente,com uma força inversamente proporcional à centralidade do lugar.

A estação do metrô é sempre uma referência, embora relativamente pelo contexto. Em Paris, Londres, Tóquio ou Nova Iorque o metrô é uma entre as várias chaves de leitura possíveis. É um sistema que se estende no espaço, tecendo com os outros fatos urbanos uma rede cujos nós vêm a ser oque Jane Jacobschama metaforicamente de "incêndios" focos de origem e de manutenção da vida nas cidades?

Em São Paulo o metrô é exceção, não é um sistema abrangente, ainda que do estrito ponto de vista do transporte esteja integrado à área metropolitana por linhas de ônibus e de trem. Nesta situação de excepcionalidade as estações têm seu grau de referência aumentado e isto se reflete na paisagem como fato arquitetônico, urbanístico e paisagístico.

A estações do metrô não possuem a "carga emocional" das estações de trem, pois fazem parte do cotidiano, nem a aura pioneira das estações de subúrbio, pois se instalaram em áreas já urbanizadas. Ainda assim não é desprezível a sua capacidade de conferir identidade aos lugares e de adquirir outros significados que não os diretamente relacionados à função transporte, como se pode inferir das entrevistas que a Companhia do Metrô realizou com a população lindeira a algumas estações ${ }^{8}$

Pode-se dizer que as estações de trem ou de metrô, em que pesem as diferenças entre elas, constituem "elementos primários" da vida urbana, atuando como núcleos de agregação para uma determinada área'. Pela frequiência com que estes elementos primários estão associados a praças seria possível falar da existência de um "tipo composto": estação + praça. Em certos casos este binômio pode tornar-se uma forma de expressão de centralidade para uma cidade, um subúrbio ou um bairro.

É necessário estudar mais detalhadamente o segundo termo deste binômio. A praça aparece como forma de centralidade na cidade arcaica, grega e romana. Entre os gregos a centralidade se manifesta num espaçoaberto definido por marcos, a Ágora, que se liga ao Cosmos, ao mesmo tempo que é o centro urbano. A cidade grega se organizou como "um espaço político homogêneo, onde ocentro só tem valor privilegiado, precisamente porque, em sua relação com ele, todas as posições diversas que ocupam os cidadãos aparecem simétricas e reversíveis" 
Ofórum romano tambémé um espaço vazio, mas colocadoem evidência pelos edifícios que o cercam. Éo centro urbano e também o centro do "mundo subterrâneo dos mortos e das almas"'11

Ainda numa praça se realizará a centralidade nas cidades medievais. Não é ligada ao Cosmos nem ao mundus ${ }^{12}$. A centralidade urbana medieval acolhe os produtos e as pessoas, reúne o religioso e o econômico num espaço que, de início, não estava submetido a uma organização morfológica pré-estabelecida, o que pode ser explicado pela própria concepção medieval de espaço. Esta concepção, baseada na Física de Aristóteles, tende a identificar o espaço com o vazio que está entre as coisas, estas sim definidas por suas qualidades intrínsecas. Os espaços intersticiais são desprovidos de significado próprio; são agregados às coisas que envolvem. Mesmo assim nos largos, decorrência fortuita da disposição dos edifícios, se realizavam as feiras, as festas, o contato social. $\mathrm{O}$ valor de uso é ali predominante. Assim também foi entre nós: "A sucessão de largos, pátios e terreiros na cidade brasileira articulava a sua trama viária modesta alimentava a vidadas suas ruas. Como tudo maisessesespaços públicoseram irregulares em geral (...). A irregularidade das praçasno Brasil sugere uma Idade Média que não conhecemos" $(. . .)^{13}$.

Nos primeiros séculos do período seguinte, $\mathrm{o}$ chamado período moderno ${ }^{14}$, o espaço urbano vaiser objetode todos oscuidados. Uma novaconcepçãodeespaço presideaesta transformação. O "vazio" que está entre as coisas passa a ser entendido como um continuum homogêneo, uma grandeza matemática passível de domínio e de organização racional ${ }^{15}$.

"O espaço chegou a ser uma categoria da mente, uma abstração pura, que assume um valor real e concreto enquanto condicionado à operante atividade do homem." ${ }^{\text {"16 }} \mathrm{A}$ praça monumental, buscando o prazer visual e cinestésico na harmonia das formas geométricas, concretiza a nova concepção de espaço e se confirma como o centro urbano, a expressão do poder, o lugar do espetáculo.

O nosso urbanismo tradicional produziu raras praças representativas desta concepção espacial, mas as poucas que houve cumpriram primordialmente a funçãode incorporar, na intencionalidade do traçado geométrico, o centro do poder. Estudando a cidade brasileira, Murillo Marx informa que a primeira praça com estas características foi a praça municipal de Salvador, seguida pela praça XV de Novembro (então largo do Paço) no Rio. "Há outros espaços semelhantes e com um significado regional como a praçadaRepública do Recife, olargo de São Franciscona SãoCristóvão sergipana, dois espaços cívicos notáveis em Minas Gerais e a praça Marechal Deodoro, em Porto Alegre. A história e o desenho variam, porém todas reúnem prédios públicos importantes e realçam uma significação que transcende a sua cidade. O sonho e o papel efetivo de uma capital."'17 
Em São Paulo, os espaços livres públicos serão objeto de cuidados especiais somente a partir das três últimas décadas do séc. XIX e início do séc. XX, quando "as ruas, os largos e os jardins públicos da cidade perderam aqueles traços nústicos que traziam do tempo em que a povoação não passava de um pequeno arraial de sertanistas (...). Retificaram-se ruas, regularizaram-se velhos largos tortuosos e desnivelados (...)"18 $\mathrm{e}$ criaram-se novas praças de traçado regular (além de jardins públicos), prestigiando a área central da cidade, então sede da aristocracia do café. Entre as realizações desta época podem ser citadas: a abertura da praça do Patriarca, a ampliação do largo da Sé, do pátio do Rosário (atual praça Antonio Prado) e do pátio do Colégio (onde se concentravam opalácio do govemo e as sedes das secretarias), a regularização da praça da República, o ajardinamento do largo São Bento, do Campo Redondo (atual praça Princesa Isabel) e da praça João Mendes (onde se localizavam as repartições da Assembléia e da Câmara) e ainda a criação dos parques centrais do Anhangabaú e D. Pedro II.

As importantes transformações políticas e econômicas iniciadas no séc. XVIII refletiram-se de modo generalizado e com grande impacto nas cidades européias no século seguinte. $O$ exemplo mais significativo, por ter se tornado paradigma, foi a reforma de Paris comandada por Haussmann em meados do séc. XIX. Françoise Choay ${ }^{19}$ resume as principais características do novo urbanismo: "Primeiro, a racionalização das vias de comunicação, com a abertura de grandes artérias e a criação de estações. Depois a especialização bastante ativada dos setores urbanos (quarteirões de negócios do novo centro, agrupados em torno da Bolsa, nova igreja; bairros residenciais na periferia destinados aos privilegiados). Por outro lado são criados novos órgãos que, por seu gigantismo, mudam oaspectoda cidade: grandes lojas(...), grandes hotéis, grandes cafés, prédios para alugar. Finalmente, a suburbanização assume uma importância crescente; a indústria implanta-se nos arrabaldes as classes média e operária deslocam-se para os subúrbios e a cidade deixa de ser uma entidade espacial bem delimitada (...)"

A cidade do capitalismo industrial acaba por realizar seu próprio tipo de centro. A centralidade não se expressará pelo "espaço de contato" das ruas e praças medievais, nem pelo "espaço de espetáculo" das praças renascentistas e barrocas. A concepção moderna do espaço como grandeza matemática, como continuum homogêneo passível de organização, será tomada na sua acepção mais conveniente: "a que permite ao poder estender-se paulatinamente de um modo uniforme sobre todo o território dominado"20. A nova monumentalidadequea geometria veicula estaráligadaàeficácia da circulação, e os planos urbanísticos serão portadores da "soluçãomais imediatamente favorávelaos capitães da indústria e aos financistas que constituem então um dos elementos mais ativos da sociedade" 
Significativamente o plano que introduziu uma das modificações mais profundas na paisagem da cidade, a partir da década de 30, chamou-se Plano de Avenidas. Não que o urbanismo de inspiração haussmanniana ${ }^{22}$ se limitasse a resolver problemas de tráfego. Tinha também intenções estéticas, apoiadas em eixos monumentais e pontos focais. Isto se verifica tanto no Plano de Paris como nos elaborados desenhos de Prestes Maia para São Paulo. Ecriou um tipo específico de praça: o seu interior nãoacolhe mais "os produtos e as pessoas", talvez um monumento; a sua volta não estão dispostos os edifícios do poder, mas veículos em movimento.

Em que pesem algumas preocupações com o aspecto das cidades "o império do número havia chegado (...) e a única expressão válida do espacial era a puramente quantitativa'"23.

A organização do espaço urbano enquanto possibilidade de encontros, simultaniedade de acontecimentos, convívio de diferenças, as ruas e as praças como espaços plurifuncionais, perdem arazãode serouao menos deixam de ser uma formadominante de expressão de centralidade.

Ao rememorar São Paulo da década de 50, num pequeno artigo de jomal, Bento Prado Jr. se refere ao "estilo da sociabilidade da vida cultural" daquela época. Embora se trate de um depoimento pessoal, enfocando particularmente o "estilo da boemia intelectual", convém transcrever alguns trechos para ilustrar o final de um período da vida da cidade em que os espaços públicos ainda eram lugares de uso relevantes mesmo no cotidiano, apesar das transformações radicais que já se processavam: "O saguão da Biblioteca - relembra Bento Prado Jr. - não era no entanto uma ilha. Principalmente à noite, seus freqüentadores se espraiavam pelas imediações. A começar pelos bancos do jardim (...). A praça revelava-se excelente local para o desdobramento das tertúliaslítero-político-metafísicas (...).Local de escolha, de que nos considerávamos vagamente proprietários e ao qual não nos sentíamos relegados a contragosto, mesmo quando a falta de dinheiro fechava qualquer outra possibilidade (...). E os bares não faltavam na própria praça (...). As mesinhas de calçada (...) dispunham-se em continuidade com os bancos do jardim (...). Numa palavra, todo mundo se conhecia e São Paulo aparecia ainda como uma cidade docemente provinciana. Ninguém imaginava, creio, nesses anos 50 , como ocrescimentodemográfico em surdina iriarepercutir logoa seguir, nesse pequeno mundo, transformando tãorapidaeradicalmenteaUniversidndeeoestilodaboemia intelectual (...). Em meados da década de 60, já havíamos perdido nossa pátria paulistana’²4.

Este também foi um período em que os espaços livres públicos eram o lugar de manifestações políticas importantes e dos comícios pré-eleitorais. Em São Paulo a democracia incipiente se expressava prioritariamente nas praças públicas, como a praça da Sé e a praça Roosevelt. 
As mudanças que foram se processando não só em São Paulo, mas em escala mundial (que acabam por se refletir nas escalas locais, mas nem sempre ao mesmo tempo) conduzem a forma de vida urbana a outras direções. Henri Lefébvre aponta o centro de decisão como a forma de centralidade típica do neocapitalismo, centralidade que pode dispensar o urbano por completo, como forma e como conteúdo². Juergen Habermas pergunta "se o próprio conceito de cidade não está ultrapassado"z6.

Apesar disto subsistem certos lugares em que o caráter urbano sobrevive, mesmo não sendo mais uma forma hegemônica. Eassim como oconteúdo urbano perdura em certós espaços a despeito das forças contrárias, também persistem algumas formas que 0 expressaram com propriedade. Até que ponto são formas anacrônicas? As praças continuam a existir mesmo que empobrecidas no aspecto e esvaziadas no significado. Não são mais a referência da cidade (não seria admissível, nem possível, supor uma grande cidade contemporânea com sua totalidade representada por um sócentro, muito menos por um só elemento, como uma praça), mas podem ainda ser referência espacial paraum ou outro bairro epor vezesacolherparte da vida cotidianados cidadãos comuns, bem como parte das atividades marginais e da marginalidade. Aliás é instigante o sentido figurado da palavra margem, como "espaço livre de tempo ou de lugar"; o espaço para acomodar o que não cabe nos parâmetros da ordem. Forma e função se encontram novamente.

\section{NOTAS}

(1) LANGENBUCH, Richard Juergen. Estruturaçāo da Grande Sāo Paulo Estudo de geografia urbana. Rio de Janeiro: Fundação IBGE, 1971.

(2) Nos corredores de transportes coletivos podem haver determinados locais de parada em tomo dos quais se verificam fluxos e concentrações muito significativos. No entanto, as razões desta concentração são extrínsecas ao meio de transporte considerado e deveın ser buscadas nos fatores de localização. Já os terminais de ônibus ou trolebus podem produzir efeitos semelhantes aos das estações.

(3) PEDREGAL, Pierre Diaz. Grandeurs et servitudes des espaces publics. In: Architecture d'Aujourd' hui, n. 198.

(4) "Em muitas cidades da Europa notadamente Paris e Londres, as praças de estação, formadas em meados do séc. XIX, são insuficientes. Em Londres, diante de duas das principais estações, Victoria e Charing Cross, não há sequer praça (...). Em Paris a estação d'Orsay é servida apenas por uma pequena praça lateral (...). A estação do Norte tem à sua frente nada mais que uma rua larga... Somente a estação do Leste possui, depois das obras de 1930, uma praça regular, larga, mas pouco profunda." LAVEDAN, Pierre. Geographie des villes. Paris: Gallimard, 1959. O autor citado constata a mesma situação em Nova York e em Chicago.

(5) LAVEDAN, Pierre. op. cit. 
(6) Estações ferroviárias, no município de São Paulo, associadas a praças:

Fepasa: Domingos de Morais, Jurubatuba.

Rffsa: Vila Clarisse, Patriarca, Itaquera, XV de Novembro, Guaianazes, Eng. Goulart, Ipiranga.

(7) “(...) Recorrendo à analogia pode-se imaginar um caınpo na escuridão e supor que em tal campo há muitos incêndios de diferentes dimensões (...), alguns se acendendo, outros se apagando pouco a pouco. Cada incêndio grande ou pequeno projeta sua luz na escuridão circundante, formando assim lugares. Porém estes espaços só existem na medida em que são criados pela luz dos incêndios (...) Estes metafóricos incêndios definidores do espaço estão formados (...) por áreas onde os usos diversos próprios de uın a cidade e os usuários se ajudam e sustentam reciprocamente de uma maneira compacta, densa e animada."

JACOBS, Jane. Muerle y vide de las grandes cirdades. Madrid: Ediciones Peninsula, 1973.

(8) Os resultados destes trabalhos estão sintetizados em:

Estratégia de implantação da estação Santa Cecília - Gerência de Operações da Cia. do Metropolitano de São Paulo.

Implanlação das estações Carrão e Penha: avaliação junto à população lindeira - 1986 - da Cia. do Metropolitano de São Paulo.

A praça da República: Expectativas do impacto do metrô no contexto urbano - Cia. do Metropolitano de São Paulo.

- Grupo de usuários A/B1, 1986 - Gerência de Operações da Cia. do Metropolitano de São Paulo.

(9) "(...) O conceito de área deve ser acompanhado de um conjunto de elementos determinados que tenham funcionado como núcleos de agregação. Estes elementos urbanos de natureza preeminente têm sido considerados como elementos primários, enquanto participam da evolução da cidade no tempo de maneira permanente, identificando-se frequientemente com os fatos que constituem a cidade. A união destes elementos (primários) nas áreas, em termos de localização e de construção, de permanências de plano e de permanência de edifícios, de fatos naturais ou de fatos construídos constitui um conjunto que é a estrutura física da cidade." ROSSI, Aldo. La arquitectura de la cindad. Barcelona: Gustavo Gili, 1966.

(10) VERNANT, J. Mito é pensamento entre os gregos. São Paulo: Difusão Européia do Livro, 1973.

(11) LEFÉB VRE, H.O dircito à cidade. Referindo-se aos gregos Lefêbvre comenta que "seu pensamento, bem como sua cidade se liga antes no Cosmos, distribuição luminosa dos lugares do espaço, do que ao mundo, passagem, corredor das trevas, errância subterrânea. Esta sombra pesa sobre o Ocidente, mais romano do que helênico."

(12) Mııdıs' inundo subterrâneo, os infernos. QUICHERAT, L. Novíssimo dicionário latino portuguez. Rio de Janeiro: B. L. Gamier, 2ª edição.

(13) MARX, Murillo. Cidade brasileira. São Paulo: EDUSP/Melhoramentos, 1980.

(14) Período da história humana, que ainda não chegou ao fiın (...), que nasce na Europa da Idade Média, (...) e que se acelera no séc. XVI e sobretudo no XVII”. DUPUY, Jean Pierre. Introdıção à crílica da ecologia política. Rio de Janeiro: Civilização Brasileira, 1980. (15) OCAÑA, Luis Morell. Estructuras locales yordenación del espacio. Madrid Instituto de Estudios de Administración Local, 1978. 
(16) RIOSSECO, G. Spazio, evoluzione del concetto in architectura. In: OCAÑA, Luis Morell. op. cit.

(17) MARX, Murillo. op. cit.

(18) BRUNO, Ernani da Silva. História e tradiçōes da cidade de São Paulo. Rio de Janeiro: José Olympio, 1954.

(19) CHOAY, Françoise. O Urbanismo. São Paulo: Perspectiva, 1979.

(20) OCAÑA, Luis Morell. op. cit.

(21) CHOAY, Françoise op. cit.

(22) Há idéias e ações que transcedem o tempo c o espaço em que foram produzidas. $O$ prefeito Olavo Setúbal, em 1977, invocou o barão Haussmann para justificar a intervenção no corredor leste-oeste, em entrevista a $O$ Estado de $S$. Paulo em 14.09.75. In: Pesquisa realizada por Maria Cecília Cardoso para a dissertação de mestrado $O$ Metrô c a Urbanizaçāo de São Paulo. FAUUSP, 1983.

(23) OCAÑA, Luis Morell. op. cit.

(24) Artigo publicado na Folla cle S. Paulo - Folhetim de 22 de janeiro de 1988.

(25) "O centro de decisão não reúne mais nem as pessoas nem as coisas, mas sim as informações, os conhecinentos. Inscreve-os numa forma eminentemente elaborada de simultaniedade: a concepção de conjunto incorporado no cérebro eletrônico, utilizando a quase instantaneidade das comunicações, superando os obstáculos ...". Lefêbvre, H. op. cit. (26) “... impõe-se perguntar se o próprio conceito de cidade não está ultrapassado. As marcas da cidade ocidental (...), da cidade burguesa na alta Idade Média européia, da nobreza urbana na Itália do norte renascentista, da capital dos principados, reformada pelos arquitetos barrocos da casa real, essas marcas históricas confluíram em nossas cabeças até formarem um conceito difuso e multiestratiticado (...). Nosso conceito de cidade liga-se a uma forma de vida. Esta contudo se transformou a tal ponto que o conceito dela derivado já não logra alcançá-la. HABERMAS, J. Arquitetura inoderna e pós-modema. In: Novos Estudos CEBRAP, n. 18, set. 1987. 